\title{
A Pleiotropic Mutant for Male Sterility and Spindly Branching at the $s b$ Locus in Common Bean
}

\author{
Mark J. Bassett ${ }^{1}$ \\ Vegetable Crops Department, Institute of Food and Agricultural Sciences, University of Florida, \\ Gainesville, FL 32611
}

Additional index words. Phaseolus vulgaris, induced mutation, inheritance

\begin{abstract}
The inheritance of an induced mutant for spindly branch and male sterility (SBMS) was investigated in common bean (Phaseolus vulgaris $L$.) in $F_{2}$ and backcross populations. The results support the hypothesis that the mutant is controlled by a single recessive gene. Extensive breeding work with SBMS, involving several thousand $F_{2}$ progeny, produced no recombinant of the types expected if two closely linked genes controlled the character. Therefore, a single pleiotropic gene apparently controls SBMS. Allelism tests demonstrated that SBMS is allelic with $s b$ but not with $s b-2$ and $s b-3$. The gene symbol $s b^{m s}$ is proposed for SBMS because it is a new allele at $s b$, with the order of dominance being $S b>s b>s b^{m s}$. Various ways to exploit the new mutant for marked male sterility are discussed.
\end{abstract}

The linkage map of common bean includes only 40 markers (Gepts, 1988), and there are insufficient natural markers in common bean that are favorable for efficient mapping. In 1979, a program was initiated to induce marker mutations in common bean to provide additional material for mapping and to produce new variability that could be exploited in basic research and plant breeding. One useful type of mutation for which I am searching is genie male sterility. There now is not a single male sterility mutant in common bean that is generally available for exploitation. There is only one previous report of a stable genie male sterility in common bean (Mutschler and Bliss, 1980), and this source has a complex inheritance that is not yet fully understood (Ashraf and Bassett, 1986; Bassett, 1989). Although there is no genie male-sterile (with complete ovule fertility) available to bean breeders and geneticists, there is a close substitute, the indehiscent anther (ian) character (Bassett, 1989; Wyatt, 1984). This mutant prevents pollen from being shed and effectively emasculates the plant, but no practical exploitation of ian has yet been reported.

This paper presents evidence that a marked male sterile mutant gene was induced in common bean and has potential for exploitation in basic research and applied breeding programs.

\section{Methods and Materials}

Origin of materials. Three dry bean breeding lines, 182-1, B-128, and B-351, were used in a program to induce marker mutations.. These lines have small, black seeds and half-runner habit and were developed and released by the Tropical Agricultural Research Station, Mayaguez, Puerto Rico. Dry seed of these lines were treated with $200 \mathrm{~Gy}$ of gamma radiation and planted in the field in 1982 to produce $\mathrm{M}_{2}$ seed. Mature seed was harvested from individual $\mathbf{M}_{1}$ plants and planted in more than 700 separate $M_{2}$ field plots in 1983. Most $\mathbf{M}_{2}$ plots had $\approx 100$ plants, except where seed was limiting. These populations were observed for mutant plants at weekly intervals. Four plots segregated for the spindly branch marker mutant, viz., 3-99, 3-

\footnotetext{
Received for publication 2 Apr. 1990. Florida Agr. Expt. Sta. Journal Series no. R-00432. This research was supported in part by funds from the USDA/ Special Grants program (Section 406). The cost of publishing this paper was defrayed in part by the payment of page charges. Under postal regulations, this paper therefore must be hereby marked advertisement solely to indicate this fact.

${ }^{1}$ Professor of Horticulture.
}

100, 3-146, and 3-296. The spindly branch mutants from 3-99, 3-100, and 3-146 have been reported previously (Awuma and Bassett, 1988; Bassett, 1990) and have been given the gene symbols $s b, s b-2, s b-3$, respectively. The spindly branch mutant from plot 3-296 is the subject of this paper.

Bumblebee pollination. One of the difficulties of searching for male sterility mutants in $\mathrm{M}_{2}$ populations at Gainesville, Fla., is the presence of large populations of bumblebees that efficiently pollinate bean. Segregants for male sterility are so thoroughly pollinated that one cannot rely on barren or late-maturing plants as indicators of male sterility. When a marked malesterile mutant occurs, its progeny "revert" to normal when grown in the greenhouse, i.e., the presumed $\mathrm{M}_{3}$ progeny test is in fact an $F_{1}$ progeny derived from outcrossing in the field. Such materials must be tested again in the field in $\mathbf{M}_{4}$ or $F_{2}$, as the case may be. If the line segregates again for the mutant, it is a prime suspect for a marked male-sterile, i.e., a pleiotropic mutant that controls the expression of male sterility and a morphological marker character.

Inheritance tests. Plot 3-296 was derived from breeding line 182-1. Seeds were harvested from the single plant in 3-296 showing the spindly branch phenotype. In Fall 1983, nine plants were grown in the greenhouse from seed of this mutant. All nine plants had completely normal phenotype, indicating that cross-pollination had occurred and, perhaps, the mutant selection was also male-sterile. Putative $\mathrm{F}_{2}$ seed were harvested and bulked for progeny testing. The $\mathrm{F}_{2}$ seed were planted in the field in Spring 1984 in plot 4-519, which segregated for spindly branch plants. The plot was covered with netting to exclude bumblebees. The flowers of spindly branch plants were examined for anther development and pollen shed. At maturity, the spindly branch plants were examined for pods developed from self-pollination, and a search was made among nonspindly plants for barren plants.

Spindly branch segregants in plot 4-519 also were backcrossed by hand to $182-1$. The $F_{1}$ progeny were grown in the greenhouse, and $\mathrm{F}_{2}$ seed were planted in the field in Spring 1985 in plot 5-1, which was covered with netting to exclude bumblebees. About 3 weeks after flowering, plants were classified into fertile and male-sterile segregants on the basis of pod set, i.e., fertile plants had a full pod set and male-sterile plants, although flowering profusely, did not set any pods. Flowers on the barren plants were examined for anther development and 
pollen shed. The plot was also searched for barren, nonspindly branch plants and fertile, spindly branch plants, hereafter referred to as recombinant phenotypes.

Further breeding work was done with the new male-sterile mutant to transfer it to other genetic backgrounds, e.g., 'Sprite' and 'Triumph' snap beans and dry bean breeding line 5-593. During 1985-87, several thousand segregating progeny were planted in plots protected with netting to determine whether the two recombinant phenotypes would appear, i.e., male-sterile plants with normal branching and spindly branch plants with male fertility. Hereafter, the spindly branch male-sterile character will be indicated with the abbreviation SBMS.

A testcross was made by crossing an SBMS segregant in 7574 with a heterozygote $F_{1}$ from 6-9 SBMS $\times$ 5-593. Line 7574 was derived from a cross of an SBMS segregant in plot 4519 by 'Sprite'. An $\mathrm{F}_{3}$ SBMS segregant from this cross was crossed and backcrossed to 5-593, and the $\mathrm{BC}_{1}-\mathrm{F}_{2}$ was designated plot 7-574. The pedigree of 6-9 also began with a cross of a SBMS segregant in 4-519 by 'Sprite', but the $\mathrm{F}_{2}$ SBMS segregant from this cross was crossed with 'Triumph'. The $F_{2}$ from this cross was designated 6-9.

Allelism tests. Allelism tests were made by crossing breeding line 7-175, which was segregating for the SBMS character from 3-296, with the other spindly branch mutants, 3-99, 3-100, and 3-146. The $F_{1}$ progeny were grown in the greenhouse and the $\mathrm{F}_{2}$ were grown in the field in 1988. These populations were classified for normal, spindly fertile, and spindly male-sterile segregants, and they were searched for any recombinant phenotypes that might appear at low frequency as described above.

\section{Results and Discussion}

Inheritance tests. The nine progeny plants from the $\mathrm{M}_{2}$ spindly branch mutant (from 3-296) were grown in the greenhouse in Fall 1983, and all had a normal phenotype. Seed from a bulk harvest of all nine progeny plants were planted in the field in Spring 1984 in plot 4-519. This material segregated for normal and spindly branch plants. An examination of the flowers on spindly branch segregants in 4-519 revealed that there was no pollen shed and that the anthers were shriveled. Crosses made with pollen from 182-1 onto spindly branch segregants resulted in normal seed development and well-filled pods. Furthermore, no pods were observed on spindly branch plants that were not the product of hand pollination. From the above experience, it was inferred that the original $\mathrm{M}_{2}$ plant was not only a spindly branch mutant but also a mutant for male sterility. Insects had cross-pollinated this plant, producing " $\mathrm{M}_{3}$ " seed that were really $\mathrm{F}_{1}$ and, therefore, had normal phenotype. The " $\mathrm{M}_{4}$ " population 4-519 was really an $\mathrm{F}_{2}$, which segregated for the recessive SBMS phenotype.

The $\mathrm{F}_{1}$ from the cross 4-519 SBMS $\times 182-1$ produced only fertile nonspindly (normal) plants. The $\mathrm{F}_{2}$ from this cross segregated for normal and SBMS plants, and no recombinant phenotypes were observed. The observed segregation in $\mathrm{F}_{2}$ for normal and SBMS plants gave a good fit to a 3:1 ratio (Table 1). This

Table 1. Segregation for the spindly branch male-sterile mutant $s b^{\mathrm{ms}}$ in the $\mathrm{F}_{2}$ population $5-1$ (from the cross $s b^{\mathrm{ms}} \times 182-1$ ) and in a testcross population, $9-402\left[7-574 s b^{\mathrm{ms}} \times F_{1} 6-9\left(+/ s b^{\mathrm{ms}}\right)\right]$.

\begin{tabular}{|c|c|c|c|c|c|}
\hline \multirow[b]{2}{*}{ Population } & \multicolumn{2}{|c|}{ Phenotypic classes } & \multirow{2}{*}{$\begin{array}{l}\text { Ratio } \\
\text { tested }\end{array}$} & \multirow{2}{*}{$\begin{array}{c}x^{2} \\
\text { value }\end{array}$} & \multirow{2}{*}{$\begin{array}{c}P \\
\text { value } \\
\end{array}$} \\
\hline & Normal & $s b^{\mathrm{ms}}$ & & & \\
\hline $5-1$ & 597 & 180 & $3: 1$ & 1.39 & 0.24 \\
\hline $9-402$ & 39 & 33 & $1: 1$ & 0.50 & 0.48 \\
\hline
\end{tabular}

result is consistent with the hypothesis that a single recessive gene controls the SBMS phenotype, although tight linkage between genes for two mutants, one for spindly branch and the other for male sterility, has not been ruled out. Therefore, I propose the gene symbol $s b^{m s}$ for the spindly branch male-sterile character, based on allelism test results to be described below.

The single recessive gene hypothesis was subsequently tested in a testcross in which $s b^{m s}$ was crossed with heterozygous plants from the cross $s b^{m s} \times 5-593$. Progeny from the testcross segregated for normal, $s b^{m s}$, and crippled seedling plants; the latter class probably due to the dosage-dependent lethality genes, D11 and $D 1-2$, reported by Shii et al. (1980). The crippled seedling problem arose from crossing Andean snap bean cultivars with MesoAmerican breeding lines. Out of a total of 113 testcross plants, 41 were crippled seedlings. The remaining 72 plants segregated for 39 normal and $33 s b^{m s}$ plants, which gave a satisfactory fit to a 1:1 segregation ratio (Table 1 ). These results support the hypothesis that a single recessive factor controls the SBMS character, contingent upon additional testing for the possibility of tight linkage between two mutant loci, one for spindly branch and one for male sterility.

During 1985-87, $5157 \quad \mathrm{~F}_{2}$ progeny (data not shown) from crosses of $s b^{m s} \times$ normal were observed for possible recombinant segregants on the assumption that the $s b^{m s}$ character is really the product of two closely linked genes, one for spindly branch and the other for male sterility. No recombinant were found, providing additional support for the hypothesis that a single, pleiotropic gene controls SBMS. If close linkage exists between two mutant loci, the recombination frequency is very low.

Allelism tests. Allelism tests of $s b^{m s}$ with $s b-2$ and $s b-3$ gave $\mathrm{F}_{1}$ progeny that were normal, and the $\mathrm{F}_{2}$ segregated in a 9 normal : 3 spindly fertile :4 SBMS ratio (Table 2). Clearly, these $s b$ mutants are not allelic with the SBMS locus. The allelism test with $s b$ gave $\mathrm{F}_{1}$ progeny that were fertile spindly branch, and the $F_{2}$ segregated in a 3 spindly fertile :1 SBMS ratio (Table 2). From these results one can infer that SBMS is a new allele at the $s b$ locus and that the order of dominance is $S b>s b>s b^{m s}$.

Female fertility. The number of seeds per pod and the number of pods per plant in SBMS segregants appear to be equal to normal segregants, provided that pollination by either insects or man is adequate and competition with nonSB plants is minimized by increasing in-row plant spacing to $20 \mathrm{~cm}$ or more. No quantitative data were taken on these yield components.

When $s b^{m s}$ was crossed to various other genetic backgrounds and carried through several segregating generations, there was no loss of recessivity of the male sterility, i.e., no seeds developed from self-pollination due to "leakiness" of the male sterility in a new genetic background. No partial restoration of fertility was observed.

Discussion of applications. There have been previous reports of marked male sterility mutants in other plant species, such as lima bean (Phaseolus lunatus L.) (Allard, 1953) and watermelon [Citrullus lanatus (Thunb.) Mansf.] (Watts, 1962). Whether such mutants are exploited for practical breeding, as was the case in watermelon (Watts, 1967), depends on many factors, such as the availability of efficient pollinating insects and great practical advantage in comparison to more conventional breeding procedures.

The spindly branch (SB) character is not easily detected in early seedling development, but as more nodes and branches are developed, segregating populations can be classified easily a few days before flowering. Thus, it is feasible to rogue out 
Table 2. Allelism tests of $s b^{\mathrm{ms}}$ with the three spindly branch mimic mutants: $s b, s b-2$, and $s b-3$.

\begin{tabular}{|c|c|c|c|c|c|c|c|}
\hline \multirow[b]{2}{*}{ Cross } & \multirow[b]{2}{*}{ Generation } & \multicolumn{3}{|c|}{ Phenotypic segregation } & \multirow{2}{*}{$\begin{array}{l}\text { Ratio } \\
\text { tested }\end{array}$} & \multirow{2}{*}{$\begin{array}{c}\chi^{2} \\
\text { value }\end{array}$} & \multirow{2}{*}{$\begin{array}{c}P \\
\text { value }\end{array}$} \\
\hline & & Normal & $s b$ (fertile) & $s b^{\mathrm{ms}}$ & & & \\
\hline \multirow{2}{*}{$s b^{\mathrm{ms}} \times s b(3-99)$} & $F_{1}$ & 0 & 56 & 0 & & & \\
\hline & $\mathrm{F}_{2}$ & 0 & 376 & 134 & $3: 1$ & 0.44 & 0.51 \\
\hline$s b^{\mathrm{ms}} \times s b-2(3-100)$ & $F_{1}$ & 36 & 0 & 0 & $0-2-1$ & 19 & 010 \\
\hline \multirow[t]{2}{*}{$s b^{\mathrm{ms}} \times s b-3(3-146)$} & $\begin{array}{l}\mathbf{F}_{2} \\
\mathrm{~F}_{1}\end{array}$ & $\begin{array}{r}292 \\
26\end{array}$ & $\begin{array}{r}84 \\
0\end{array}$ & $\begin{array}{r}124 \\
0\end{array}$ & $9: 3: 4$ & 1.43 & 0.49 \\
\hline & $\mathrm{F}_{2}$ & 296 & 95 & 142 & $9: 3: 4$ & 0.87 & 0.65 \\
\hline
\end{tabular}

all fertile segregants in a row to produce an all male-sterile row for experimental $\mathrm{F}_{1}$ seed production.

SB produces thinner and more numerous branches, which is a structural. change that persists after senescence. Even after all the foliage has dropped, the SB plants can be readily distinguished from normal, provided that the plants are spaced $\approx 20$ $\mathrm{cm}$ or more in the row. Most marked male-steriles are easily identified at flowering, but it is rare to have a marker that is also obvious at full senescence. The latter characteristic allows a breeder to enter a mature, fully defoliated field and select for male-sterile segregants without the need for previous tagging.

The $s b^{m s}$ gene can be used in the various recurrent selection schemes for plant improvement. In material segregating for SBMS, it is possible to make controlled crosses between selected plants in the field with great efficiency, or one can allow insects to make random crosses between fertile and male-sterile plants in the field. Recurrent selection might be achieved by alternating between mass selection among nonSBMS plants one year and allowing open-pollination among the self progeny the next year. Seed could be harvested from SBMS plants after open-pollination; this seed would produce the next generation, which would again be subjected to mass selection. This procedure would be particularly appropriate where the most desirable environment for mass selection does not have adequate populations of bumblebees and carpenter bees to permit effective- open-pollination. Several cycles of this procedure could produce a "landrace"-type cultivar that is highly uniform for seed color (and pattern), size, and shape; highly uniform for disease resistance; moderately uniform for plant habit; and highly variable for genes not made uniform by mass selection. Such cultivars might be more stable in their performance over years and be more widely adapted geographically.
Seed of the $s b^{m s}$ mutant is available from M.J.B. upon request.

\section{Literature Cited}

Allard, R.W, 1953. A gene in lima bean pleiotropically affecting malesterility and seedling abnormality. Proc. Amer. Soc. Hort. Sci. 61:467471.

Ashraf, M. and M.J. Bassett. 1986. Cytogenetic analysis of translocation heterozygosity in the common bean (Phaseolus vulgaris L.). Can J. Genet. Cytol. 28:574-580.

Awuma, K. and M.J. Bassett. 1988. Addition of genes for dwarf seed $(d s)$ and spindly branch $(s b)$ to the linkage map of common bean. J. Amer. Soc. Hort. Sci. 113:464-467.

Bassett, M.J. 1989. List of genes. Annu. Rpt. Bean Improv. Coop. 32:1-15.

Bassett, M.J. 1990. Three mimic mutants for spindly branch in common bean and tests for linkage with other mutants. HortScience 25:1280-1281.

Gepts, P. 1988. Provisional linkage map of common bean. Annu. Rpt. Bean Improv. Coop. 31:20-25.

Mutschler, M.A. and F.A. Bliss. 1980. Genie male sterility in the common bean (Phaseolus vulgaris). J. Amer. Soc. Hort. Sci. 105:202205.

Shii, C.T., M.C. Mok, S.R. Temple, and D.W.S. Mok. 1980. Expression of developmental abnormalities in hybrids of Phaseolus vulgaris L.J. Hered. 71:218-222.

Watts, V.M. 1962. A marked male sterile mutant in watermelon. Proc. Amer. Soc. Hort. Sci. 81:498-505.

Watts, V.M. 1967, Development of disease resistance and seed production in watermelon stocks carrying the $m s g$ gene. Proc. Amer. Soc. Hort. Sci. 91:579-583.

Wyatt, J.E. 1984. Inheritance of an indehiscent anther character in common bean. HortScience 19:670-671. 